\title{
High-Speed Time-Resolved Multispectral Imaging of a Turbulent Flame
}

\author{
Marc-André Gagnon, Pierre Tremblay, Eric Guyot and Philippe Lagueux \\ Telops Inc. \\ 100-2600 Saint-Jean-Baptiste Ave, Québec, Canada \\ marc-andre.gagnon@telops.com; pierre.tremblay@telops.com; eric.guyot@telops.com; philippe.lagueux@telops.com
}

\section{Extended Abstract}

Characterization of turbulent flames typically requires high temporal and spatial resolution on a wide field-of-view in order to cope for the unpredictable behaviour of these systems. Infrared imaging first appears to be a well-suited diagnostic tool for combustion reactions. However, it is well known that many common combustion gases such as water vapour $\left(\mathrm{H}_{2} \mathrm{O}\right)$ and carbon dioxide $\left(\mathrm{CO}_{2}\right)$ selectively absorb and emit infrared radiation over a very narrow spectral range. Therefore, information about spectral emissivity using infrared imaging is required in order to obtain quantitative results.

Using infrared imaging in combination with band-pass filters provides spectral information and has already been used for characterizing different stages of combustion experiments [1-3]. However, if only one spectral filter is used at a time, it limits the use of this technique to steady-state (e.g. laminar flames) systems [1] and/or cyclic phenomena [2, 3]. Recording spectral information at high temporal resolution is then required in order to achieve characterization of unsteady combustion phenomenon like turbulent flames.

In this work, ignition and steady-state combustion of hot methanol vapours were investigated using high-speed midwave infrared (MWIR, 3-5.5 $\mu \mathrm{m}$ ) multispectral imaging. The camera was equipped with an 8-position fast-rotating filter wheel. The infrared filter selection included bandpass filters associated with $\mathrm{CO}_{2}, \mathrm{H}_{2} \mathrm{O}$, carbon monoxide (CO) and hydrocarbons (HCs) infrared self-emission spectral ranges. A neutral density filter was also used in order to get a broadband image of the scene. Image acquisition was carried out at $800 \mathrm{~Hz}$ in a fully synchronized mode with the filter wheel rotating at 6000 revolutions per minute. This lead to an effective frame rate of $100 \mathrm{~Hz}$ per spectral band allowing detailed observation of turbulences while gathering spectral information at the same time. In the experiment, a flame was placed right above, but not in contact with, a recipient containing hot methanol. Once the flame reached the area where methanol vapours were in sufficient concentration, the flame propagated and ignited the reservoir. Significant amounts of unburnt methanol vapours could be detected above the reservoir in the instant following the burst caused by the ignition.

In-band radiance profiles (IBR) were obtained by combining the results of the different spectral bands. A simple radiative transfer model was developed according to the phenomenology of methanol combustion. Temperature and gas column density estimates were obtained through the simulation of IBR profiles. Flame temperatures on the order of $900 \mathrm{~K}$ were estimated by using spectral information. These results are significantly higher than the $400-500 \mathrm{~K}$ values measured by broadband infrared imaging. The results illustrate the potential of high-speed multispectral imaging as a quantitative diagnostic tool for characterizing turbulent flames.

\section{References}

[1] D. Han, Y. Yang, R. K. Kapaku, and J. P. Gore, "Quantitative narrowband infrared imaging of a turbulent lean premixed flame," in Proceedings of the $9^{\text {th }}$ US National Combustion Meeting, Cincinnati, OH, 2015, vol. 9, $2 \mathrm{H} 07$.

[2] W. E. Eagle, L.-M. Malbec, and M. P. B. Musculus, "Comparing vapor penetration measurements from IR thermography of $\mathrm{C}-\mathrm{H}$ stretch with schlieren and LIF during fuel injection in a heavy-duty diesel engine," in Proceedings of the $9^{\text {th }}$ US National Combustion Meeting, Cincinnati, OH, 2015, vol. 9, 2 C12.

[3] E. Mancaruso, B. M. Vaglieco, and L. Sequino, "Using 2d infrared imaging for the analysis of non-conventional fuels combustion in a diesel engine," SAE Int. J. Engines, vol. 8, no. 4, pp. 1701-1715, 2015. 